\title{
El poder creador: tipos de poder y estrategias de sujeción en la frontera sur de Chile en la época colonial
}

Guillaume Boccara

(CERMA-EHESS, París)

En este trabajo se analiza la evolución de las estrategias y métodos utilizados por los españoles para dominar a los pueblos autóctonos (reche o mapuche) del centro-sur de Chile. Se pretende demostrar que existe una diferencia radical entre el modelo de conquista imperante durante el primer siglo (1550-1641) y los dispositivos de sujeción que se asentaron después (1641-1810), pasando de una máquina de conquista soberana, que remite a un ejercicio violento del poder y que tiende a funcionar a partir de la integración-exclusión, a otra que se funda en una empresa de civilización-asimilación de los pueblos sin policía. Asimismo, se pone en evidencia el papel central jugado por los jesuitas en el paso de un modelo a otro.

Hasta una época reciente, los tres siglos de contactos hispano-mapuche eran percibidos básicamente a través del prisma guerrero. A tal punto que la narración de los acontecimientos de la frontera sur del Reino de Chile casi se limitaba a la enumeración de las contiendas entre dos protagonistas que poco a poco, a través de siglos de violencia e incomprensión, se habían ido constituyendo en auténticos enemigos hereditarios. La historia de la Araucanía consistía en una lista de batallas bajo la idea de que el carácter belicoso y naturalmente salvaje de los araucanos había mantenido en jaque la empresa conquistadora y civilizadora del invasor español. Este marco interpretativo propició la construcción de la figura del araucano como un guerrero indomable que, a pesar del contacto plurisecular con el español, no parecía sacar ningún provecho de esa proximidad y de la potencial influencia de gentes portadoras de una cultura superior. Así pues, desde la llegada de los conquistadores hasta los primeros sobresaltos de la guerra de independencia, la Araucanía tan solo había sido el teatro de una lid sin piedad en la que el salvaje y resistente araucano había podido dar rienda suelta a sus instintos más primitivos; la historia de las relaciones hispano-indígenas se reducía, de alguna manera, a la de la guerra.

En oposición a esta visión dominante de la Araucanía como espacio guerrero, a principios de los años 80 se desarrolló en Chile una nueva corriente historiográfica (conocida bajo el nombre de Estudios Fronte- 
rizos), que se propuso tomar en cuenta las relaciones fronterizas en toda su complejidad, llegando a la conclusión de que la guerra no había sido la única modalidad del contacto entre españoles y mapuche. En efecto, según los estudiosos de esta corriente, se puede distinguir entre una primera etapa claramente bélica (1536-1655) y una segunda caracterizada por la convivencia pacífica (1655-1883), en la que los contactos fronterizos y las instituciones de frontera (misión, comercio, parlamento, capitanes de amigos y comisario de naciones como agentes pacíficos del poder español) sustituyeron paulatinamente a la guerra de conquista y al contacto violento. ${ }^{1} \mathrm{El}$ interés de estos estudiosos se concentró, por lo tanto, en aquello que los anteriores habían dejado escapar, cegados por el mito de la guerra permanente, a saber: la naturaleza de los contactos fronterizos en época de paz y las transformaciones socioculturales a que dieron lugar.

Aunque estos trabajos se caracterizan por su gran diversidad, hay sin embargo una serie de hipótesis y conclusiones comunes a todos ellos y que podríamos resumir de este modo:

1) A partir de la segunda mitad del siglo XVII, se instaura un periodo de paz o de convivencia pacífica que deja atrás la antigua lógica guerrera. 2) Esta paz es tanto el producto histórico y lógico de los roces fronterizos y de las relaciones de dependencias que, poco a poco, se tejieron entre ambos sujetos como el resultado de una clara voluntad de las autoridades españolas de establecer vínculos con los indígenas en la medida en que la guerra de conquista había fracasado. 3) Dicha paz se apoya en varias instituciones que expresan el aspecto voluntarista de esta política de acercamiento (misión, parlamento, comercio, intermediarios sociopolíticos o tipos fronterizos), y se afianza mediante un profundo proceso de mestizaje y de una permanente e intensa circulación de valores, objetos, ideas e individuos. 4) Los conflictos violentos que perturban esporádicamente la paz deben ser interpretados en el marco de esa misma dinámica de convivencia pacífica, y no como una reacción indígena a la voluntad hispana de dominarlos. Los estallidos guerreros se explican esencialmente en razón del desfase en el grado de desarrollo cultural entre ambas sociedades: los indígenas no pueden comprender normas de conducta que no corresponden a su estadio cultural (trabajo en las minas para producir un excedente, voluntad de difundir la palabra de un Dios omnipotente, política de reducción a pueblos, etc.). 5) La existencia de un espacio fronterizo estable, en donde se

1 Villalobos, Sergio y al.: Relaciones fronterizas en la Araucanía, Santiago de Chile, 1982. 
afianzan lazos de dependencias y en el que circulan cosas y personas, tiene como consecuencia lógica la aculturación progresiva del indígena y su asimilación pacífica a la sociedad de mayor cultura. 6) Por último, este largo proceso de deculturación de los grupos mapuche y su frenético interés por los productos materiales y culturales de una civilización superior o más avanzada constituiría la primera etapa en la incorporación pacífica de la Araucanía al Estado chileno a fines del siglo XIX.

No voy a emprender aquí una crítica pormenorizada de los postulados teóricos etnocéntricos y evolucionistas que subyacen en los Estudios Fronterizos y que llevan a sus autores a considerar que un grupo de "cultura inferior" debe, necesariamente, estar sometido a un proceso de aculturación impuesta para sufrir luego una desestructuración de su organización sociopolítica y una dilución de su identidad específica. ${ }^{2}$ Sin embargo, sí voy a detenerme en sus concepciones implícitas acerca de las nociones de paz, guerra, política y resistencia.

Desde esta perspectiva considero que los Estudios Fronterizos, a pesar de su interés explícito por los procesos de mestizaje y por la dinámica sociocultural, siguen prisioneros de una visión de lo político y de la cultura en gran parte tradicional. Así, en lo que concierne a su filosofía política implícita, tienden a considerar la guerra como el único modo de imponer un orden; de tal manera que, una vez desaparecida la voluntad de conquistar los territorios indígenas por las armas, parece desvanecerse todo tipo de empresa de sometimiento y sujeción. Dentro de este marco interpretativo, la misión, el parlamento y el comercio se nos presentan como espacios neutros del libre intercambio de objetos y valores. En este trabajo trataré de demostrar sin embargo que, lejos de ser lugares de convivencia pacífica o de paz, se trata de espacios de pacificación, y que las relaciones políticas entre ambos protagonistas, durante el segundo periodo histórico (1641-1810), deben ser consideradas como una prolongación de la guerra por otros medios. En definitiva, intentaré demostrar que el fin de la guerra de Arauco no supone la entrada a un periodo de paz sino de pacificación.

2 Para una crítica detallada de los postulados téoricos y de las conclusiones de los Estudios Fronterizos véase Boccara, Guillaume: "Notas acerca de los dispositivos de poder en la sociedad colonial-fronteriza, la resistencia y la transculturación de los reche-mapuche del centro-sur de Chile (XVI-XVIII)", Revista de Indias, vol. LVI, no. 208, Madrid, 1996, págs. 659-695; Boccara, Guillaume: Des Reche aux Mapuche: analyse d'un processus d'ethnogenèse (changements et continuités chez les indiens du centre-sud du Chili durant l'époque coloniale, XVIème-XVIIIème siècle), París, École des Hautes Études en Sciences Sociales, Tesis de Doctorado, 1997, 2 vols., págs. 234-267. Se acaba de publicar una versión corregida y más corta de esta tesis: Guerre et ethnogenèse Mapuche dans le Chili colonial. L'invention du Soi, París, 1998. 
El otro problema que surge de la lectura de estos trabajos tiene que ver con su concepción sustantivista o esencialista de la cultura. La entidad e identidad cultural son consideradas como cosa dada a priori, como una esencia que únicamente se transformaría por contaminación o por souillu$r e$. En consecuencia, toda modificación de la tradición y de la lógica sociocultural (paralizadas en una esencia eternal, ahistórica) es percibida como una pérdida de la pureza original y como la primera etapa hacia un proceso de total asimilación. Empero, los últimos estudios etnohistóricos permiten afirmar que, lejos de haber desaparecido a través de una mecánica de la aculturación impuesta, los grupos nativos entraron en una dinámica de reestructuración y de redefinición de su identidad, cuya expresión más notable fue la emergencia de una nueva identidad y entidad étnica (los mapuche) mediante un largo proceso de etnogénesis. ${ }^{3}$

Antes de seguir adelante quiero precisar que, si bien aquí retomo la periodización establecida por los Estudios Fronterizos, le doy un sentido y un contenido radicalmente diferentes. En primer lugar, porque considero que no hubo una ruptura nítida o paso brusco y brutal de un periodo histórico a otro. La transformación del modelo de conquista se efectuó progresivamente mediante desplazamientos, deslizamientos y desmoronamientos. En segundo lugar, porque no considero que estos dos periodos se opongan como la guerra se opone a la paz. En efecto, una y otra deben ser analizadas como un sistema o como las dos facetas de una misma máquina de poder. Durante el segundo periodo ya no se trata de reducir a los indígenas por las armas para establecer la pax hispánica, sino de pacificar a individuos y grupos, es decir, de politizarlos y civilizarlos mediante una labor permanente y continua sobre sus cuerpos y mentes. La lógica de guerra-paz desaparece poco a poco, instaurándose un nueva máquina civilizadora que funciona a partir de la inculcación-interiorización de nuevas normas y de la reforma de las costumbres consideradas como salvajes. Se trata de hacer del indio un verdadero hombre y de su colectividad una verdadera sociedad; un proyecto fundamentalmente humanista ${ }^{4} .$. y "etnocida".

3 Sobre el tema de las transformaciones y reestructuraciones de los grupos reche-mapuche durante el periodo colonial véase Lázaro Avila, Carlos: La transformación sociopolítica de los araucanos (siglo XVII), Madrid, Univ. Complutense, Tesis de Doctorado, 1995; León Solis, Leonardo: Maloqueros y conchavadores en Araucanía y las Pampas, 1700-1800, Temuco, 1991; Boccara: Des Reche aux Mapuche..., 1997.

4 En el sentido de un espíritu pedagógico y de perfectibilidad, de un proyecto educativo que toma en cuenta la responsabilidad humana, el aspecto lingüístico y la voluntad de reforma de los usos y costumbres con el fin de mejorarlos. Sobre este aspecto véase Bustamante García, Jesús: "Retórica, traducción y responsabilidad histórica: claves humanísticas en la obra de Bernardino de Sahagún", en Ares Queija, Berta et al.: Humanismo y visión del otro en la España moderna, Madrid, 1992, págs. 243-375. 


\section{El poder soberano y los dispositivos concretos de la conquista: guerra y paz en la Araucanía (1545-1641)}

Como ya he mostrado en otro trabajo, ${ }^{5}$ este periodo se caracteriza por la guerra a sangre y fuego y una paz esporádica. Esta primera tentativa de conquista por las armas funciona a partir de unos determinados dispositivos de poder - aplicando la terminología foucaltiana-, como son la expedición guerrera, la encomienda, la esclavitud, la maloca, el fuerte y, a nivel discursivo, el requerimiento. Dichos dispositivos, que se inscriben dentro de un diagrama de poder que podríamos llamar soberano, se fundamentan en una mecánica que se propone someter a masas y funcionan a partir de un principio que podríamos definir como el derecho a matar. No exigen un control continuo sobre los individuos ni requieren un conocimiento exhaustivo y preciso del sujeto sobre el que se ejerce la acción. El ejercicio del poder en este caso tiene como objetivo incorporar masas y territorios a un espacio de soberanía real y reunir bienes y riquezas mediante la extracción de un tributo. Como vamos a ver, este diagrama de poder pre-disciplinario (denominado así por Foucault $)^{6}$ o pre-civilizador gira en torno a la figura omnipotente del soberano. En caso de rebelión, por ejemplo, el ofendido es el propio rey, pues la ley equivale a la voluntad del soberano. Del mismo modo, los fuertes en territorio enemigo y el camino real son siempre la significación de un poder soberano, y el propio requerimiento representa la quintaesencia de este poder, que engloba incluso lo religioso. En fin, dentro de este diagrama, el poder encuentra su legitimidad en la persona real y se impone desde el exterior sobre una masa de sujetos, esencialmente a través de la modalidad de represión-coacción. Veamos, pues, con un poco de detalle cada uno de los dispositivos que funcionan durante este primer periodo.

\section{La lógica de guerra-paz en Araucanía y la afirmación del poder real}

En el caso de las expediciones guerreras, realizadas cada verano por las tropas españolas, tenemos un tipo de ejercicio del poder bastante discontinuo. De hecho, estas empresas no suponen un control permanente sobre las comunidades rebeldes; primero, porque sólo se llevan a cabo en una épo-

5 Boccara: "Notas...", 1996.

6 Véase Giard, Luce (bajo la dirección de): Michel Foucault, lire l'oeuvre, París, 1992. 
ca del año y, segundo, porque son localizadas y delimitadas en el espacio. En efecto, los gobernadores siguen un "recorrido punitivo" de comunidad en comunidad y, luego, se vuelven a invernar en los fuertes, que funcionan como enclaves protegidos en territorio enemigo. Esas entradas, discontinuas y represivas, tienen como objetivo afirmar el poder real, dando lugar a masacres y castigos con el fin de reducir y amedrentar a los indios rebeldes. La necesidad de localizar geográficamente a las diversas comunidades no interviene como un modo de vigilarlas, sino como un instrumento que permite realizar con cierta eficacia una labor esporádica de represión.

En mi opinión, es en el marco del ejercicio de un poder soberano como hay que entender la extrema violencia de la represión y el aspecto espectacular y público de las mutilaciones corporales inflingidas a los indígenas apresados durante las expediciones. Las narraciones de masacres de niños y mujeres así como la práctica de mutilaciones (cortarles la nariz, las manos, la cabeza) pueden interpretarse como la expresión de la voluntad española de restablecer una soberanía dañada o de castigar un crimen de lesa majestad. Desde esta perspectiva, se parecen a las ceremonias de suplicio, que aspiraban a manifestar de manera clamorosa el poder real. No se trata aquí de castigar la violación de un pacto político, como veremos que ocurre en el segundo periodo, sino de restablecer y expresar simbólica y físicamente la fuerza soberana del rey. El carácter inhumano de las masacres y mutilaciones nos remite al ejercicio de un poder que no tiene la humanidad por medida. Es así como, después de la victoria de los españoles en la batalla de Andalien (1550), Pedro de Valdivia mutiló a los indios prisioneros y les envió de vuelta a sus comunidades a modo de escarmiento:

...murieron trescientos indios y prendiéronse más de doscientos. Y de aquéstos mandó el gobernador castigar, que fue cortalles las narices y manos derechas...Hecho este castigo, les habló el gobernador a todos juntos, porque había algunos caciques y prencipales, y les dijo y declaró cómo aquello se usaba con ellos porque les había enviado a llamar muchas veces y a requerir con la paz, diciéndoles a lo que venía a esta tierra, y que habían recibido al mensajero, y que no solamente no cumplieron aquello, pero vinieron con mano armada contra nosotros... que lo mismo se haría con los demás que no viniesen a dar obediencia y a servir a los españoles. De esta suerte se enviaron estos indios a sus casas para en castigo de ellos y exemplo para los demás.?

La noción de requerir que aquí aparece remite de manera directa al famoso Requerimiento, el cual de manera casi caricaturesca afirma el poder absoluto del soberano sobre unas masas y unos territorios indeterminados

7 Vivar, Gerónimo de: Crónica de los Reinos de Chile, Madrid, 1988, págs. 249-250. 
y sobre unos grupos desconocidos y definidos como súbditos del rey. Este texto, escrito en 1513 y donde se señala que el Papa, jefe de la cristiandad, había otorgado al rey el derecho a conquistar y evangelizar los territorios habitados por pueblos bárbaros, tiene todas las características de lo que John Austin llama un enunciado performativo. ${ }^{8}$ Era precisamente con la lectura de este texto y del ritual que lo acompañaba cómo los españoles tomaban posesión de un territorio y transformaban a sus habitantes en vasallos de su rey. Además de enunciar los derechos del soberano y los deberes de sus sujetos, el requerimiento tenía también valor de amenaza ya que el no respeto del poder real hacía automáticamente de la guerra una causa justa y de la esclavitud una institución legítima. Tal y como señala Todorov, el objetivo de los españoles no era la comunicación. ${ }^{9}$ La prueba más clara es que este texto se decía en castellano y a veces sin intérprete. Por otra parte, esta guerra justa y esta esclavitud no debían efectuarse de una manera indeterminada. Los vasallos insubordinados debían ser castigados con crueldad y sin piedad. ${ }^{10}$

Antes de seguir adelante, es necesario interrogarse sobre la relación que existía entre lo político y lo religioso en la empresa de conquista de este primer periodo. A diferencia de lo que ocurre en el segundo periodo, creo que la empresa de evangelización estuvo subordinada a la imposición de un marco jurídico-político de soberanía. No quiero decir con esto que lo religioso actuara únicamente como justificación de la empresa de conquista territorial, sino que el principio que rigió la instauración de los dispositivos de poder se inscribe en una lógica de la soberanía que tiene al rey como clave de bóveda. De tal modo que la evangelización no está pensada aquí como empresa de transformación de una cultura ajena o como evangelización de la cultura, sino que actúa como una modalidad de la imposición de una soberanía política trascendente y omnipotente. Como ya señalaron Bestard y Contreras (1987), en el requerimiento la problemática de la diferencia cultural está totalmente ausente. ${ }^{11}$ Se podría decir incluso que la diversidad cul-

8 Este filósofo inglés define como performativo un tipo de enunciado particular, que no es ni una descripción ni una afirmación ni una exhortación, sino una frase que, en un cierto contexto y bajo ciertas condiciones, hace que decir algo es hacerlo. Las palabras "En el nombre del Rey y de Dios tomo posesión de esta tierra" o "Te bautizo" son enunciados performativos en el sentido de que no son ni verdaderos ni falsos, no necesitan ser demostrados, no describen, pero hacen. Austin, John L.: Quand dire c'est faire, París, 1970.

9 Todorov, Tzvetan: La conquête de l'Amérique. La question de l'autre, París, 1982, págs. 161-230.

10 Véase el texto reproducido en Bestard, Joan y Contreras, Jesús: Bárbaros, paganos, salvajes y primitivos. Una introducción a la Antropología, Barcelona, 1987, págs. 40-41.

11 Ibídem, pág. 42. 
tural es el punto ciego de este texto, que expresa la voluntad de integrar a unas masas indeterminadas y unos territorios sin límites claramente fijados. Este aspecto formal tendrá, por lo demás, su traducción concreta en la subordinación de la empresa de cristianización a la de conquista política. A manera de ilustración presentaré dos ejemplos de esto: el primero es el relato que hace Martín Fernández de Enciso de su experiencia del requerimiento; el segundo se refiere a las modalidades de integración de los indios amigos al aparato militar español de la frontera araucana.

El primer caso está tomado de J. Bestard y J. Contreras, quienes recogen un texto de Enciso (1519), donde se refleja de manera muy clara la subordinación antes mencionada:

Yo requerí, por parte del rey de Castilla, a dos caciques destos del Cenú, que fuesen del rey de Castilla, y que les hacía saber cómo había un solo Dios, que era Trino y Uno y gobernaba el cielo y la tierra, y que éste ha venido al mundo y había dejado en su lugar de Dios, y que este Santo Padre, como señor del Universo había hecho merced de toda aquella tierra de las Indias y del Cenú al rey de Castilla, y que por virtud de aquella merced que el papa había hecho al rey, les requería que ellos dejasen aquella tierra, pues les pertenecía; y que si quisiesen vivir en ella, como se estaban, que le diesen la obediencia, como a su señor, y le diesen en señal de obediencia alguna cosa cada año; y que si esto hacían, que el rey les haría mercedes y les daría ayuda contra sus enemigos, y que pornía entre ellos frailes o clérigos que les dijesen las cosas de la fé de Cristo, y que si algunos se quisiesen tornar cristianos, que les haría mercedes, y que los que no quisiesen ser cristianos, que no les apremiarían a que lo fuesen, sino que estuviesen como se estaban". ${ }^{12}$

Como se puede ver, la cristianización de los indios no es pensada como una condición previa a su integración, sino como una oportunidad dejada abierta por su agregación a un espacio político sometido a la soberanía del rey. La voluntad de civilizar por medio de la evangelización llegará más tarde, una vez emergida la problemática de la diferencia cultural. Obviamente, es necesario matizar esta afirmación en la medida en que es en la misma época cuando aparecen, principalmente en el seno de las órdenes misioneras, nuevas perspectivas a propósito de la toma en consideración de la diferencia cultural (el dominico Las Casas, el franciscano Bernardino de Sahagún y, más tarde, el jesuita José de Acosta). Pero a pesar de que los primeros tiempos de la conquista aparecen como un periodo de transición, que se manifiesta en la famosa disputa de Valladolid, de las prácticas de los conquistadores y de los primeros textos de la conquista se

12 Ibídem, págs. 43-44. 
puede destacar que la diferencia cultural no está todavía problematizada. En otras palabras, si bien los españoles tienen su propia concepción de la cultura y de la alteridad, ésta no funciona todavía como principio ideológico-político o elemento clave en la empresa de conquista.

El segundo ejemplo del funcionamiento concreto de este principio de soberanía que procede por integración-exclusión, a diferencia del principio civilizador que lo hace por asimilación-marginación, lo encontramos en los indios amigos del centro-sur de Chile, quienes ayudaban a los españoles en su empresa de conquista de la Araucanía, pero que, lejos de asimilarse y fundirse con las tropas españolas, disponían de sus propios escuadrones y practicaban, a la vuelta de las expediciones guerreras, sus rituales antropofágicos. Resulta muy interesante ver que las descripciones de estas prácticas bárbaras, realizadas ante la total indiferencia de los jefes españoles, se encuentren en los textos de un misionero jesuita, Diego de Rosales, quien más tarde encarnaría el nuevo modelo de conquista y civilización. He aquí lo que él escribe:

...ver que los indios amigos de los españoles hagan con los indios de guerra, que cogen, lo mismo, matandoles a su barbara usanza, sacandolos el corazon, comiendosele a vocados y haziendo flautas de sus canillas i huesos. Y assi, por no irritarlos mas y por la indecencia que trahe consigo el usarse en tierras de christianos una crueldad tan barbara, debian los Gobernadores, los Maestros de campo y sarjentos mayores no consentir mas en sus tercios semexantes atrocidades, tan contrarias a la piedad christiana. Y aunque lo escussan con que los indios amigos se sentiran de que se lo estorven, no es razon que convence, que siempre he visto que quando lo han querido estorvar, lo han hecho, y quando han querido conservar a un indio esclavo, para servirse de el o para venderle, le an librado de la muerte, y aunque los indios le han pedido para matarle, con buenas razones se le han conservado... Y siendo este uso gentilico i tan contra la christiandad i humanidad que professa la religion christiana, se debiera desterrar de las tierras de los Christianos...la condescendencia con ellos en eso es dañosa, de mal exemplo y escandalo y de que se pueden seguir grandes daños y inconvenientes, y que sin eso, se puede con razon temer no nos castigue Dios con malos succesos, por no ajustarnos con su Santa Ley i no hazer a los indios a la nuestra, sino que ellos nos hagan a la suya. ${ }^{13}$

El objetivo de los españoles era disponer de unos aliados experimentados en su empresa de integración de los espacios aún libres de la Araucanía. Para ellos el hecho de que sus aliados indígenas practicaran

13 Rosales, Diego de: Historia general del Reino de Chile, Flandes Indiano, Santiago de Chile, 1989, vol. 1, págs. 130-131. (Tanto en éste como en los demás textos de Rosales se ha hecho una nueva puntuación). 
rituales bárbaros no constituía un problema, ya que el resorte de esta primera conquista no era la cristianización o civilización de los indígenas. La preocupación de los gobernadores y maestros de campo era agregar el máximo de indígenas a sus tropas e incorporar nuevos territorios al espacio de soberanía real, sin ninguna preocupación por el aspecto religioso o cultural de dicha empresa. De ahí que los idios amigos dispusieran de sus propios escuadrones, fueran dirigidos por sus propios jefes y emplearan sus tácticas y prácticas guerreras "tradicionales". Y si bien es cierto que a la cabeza de estos escuadrones figuraba un capitán de amigos huinca, ${ }^{14}$ éste compartía su cargo con un indio y desempeñaba un mero papel de encuadramiento. Su función era esencialmente militar, con prerrogativas limitadas, y contrasta notablemente con el papel de intermediario cultural, de "agente aculturador" y con la labor de vigilancia que llegó a ejercer el capitán de amigos a partir de la segunda mitad del siglo XVII.

Además de la expedición guerrera y el requerimiento, la encomienda funcionó asimismo como otro de los dispositivos de poder cuya meta era, al menos en un primer momento, someter a masas indeterminadas con el fin de reunir bienes y riquezas mediante un uso discontinuo de la fuerza de trabajo indígena. A pesar de haber sido la fuente de numerosos conflictos entre los encomenderos y el poder real, la encomienda se inscribe dentro del diagrama de poder soberano en la medida en que opera a partir de la extracción periódica de riqueza o de fuerza de trabajo bajo la amenaza armada. Hay que señalar que la entrega de encomiendas no requería un conocimiento preciso de las poblaciones otorgadas a los distintos conquistadores que intervenían en una expedición, como bien se puede ver en la primera entrada de Pedro de Valdivia en el sur de la Araucanía. Apenas llegado a orillas del río Cautín, el extremeño procede a la distribución de encomiendas sobre un territorio delimitado de manera muy aproximada y cuyas poblaciones se conocen solamente en términos de densidad:

Luego repartí todos los caciques que hay del río para acá, sin dar ninguno de los de la otra parte, por sus levos, cada uno de su nombre -que son como apellidos y por donde los indios reconocen subjeción a sus superiores-, entre ciento y veinte y cinco conquistadores, y los repartí los levos e indios dellos de dos leguas a la redonda para el servicio de casa. E dejándolos así con un capitán hasta que, visitada bien la tierra, se hiciese el repartimiento y se diesen las cédulas a los vecinos que allí conviniese e pudiese darles su retribución. ${ }^{15}$

14 Para los reche-mapuche, el huinca era, y es todavía, el extranjero.

15 Valdivia, Pedro de: Cartas de relación de la conquista de Chile, Santiago de Chile, 1970, pág. 170. 
Es necesario señalar que este conocimiento parcial del territorio y de la demografía indígenas estuvo acompañado durante muchos años del desconocimiento de las estructuras sociopolíticas reche. Los títulos de encomiendas de las primeras décadas son bastante significativos al respecto. Las unidades sociopolíticas (lebo, rehue, cabi) son muy a menudo confundidas y la pertenencia de un grupo o cacique a un determinado agregado sociopolítico se establece de manera aproximada y arbitraria. De ahí los numerosos conflictos entre encomenderos en torno al reconocimiento de sus derechos sobre unos territorios y unas poblaciones que, a veces, se superponen.

Por otra parte, el ejercicio discontinuo y a menudo violento del poder hacía que su eficacia fuera bastante relativa. Además de generar una resistencia armada por parte de los indios, no permitía una extracción regular del tributo. Numerosos encomenderos se quejaban de que los indios de mita muy raramente se presentaban para realizar su trabajo.

El último dispositivo que parece integrarse en este diagrama soberano, imperante en el primer siglo de la conquista, es el fuerte. No se trata de hacer aquí un análisis de las estrategias militares españolas, ni tampoco de estudiar la estructura de los diferentes tipos de fortificación, sino de intentar comprender la naturaleza de la relación con el Otro que instituía el reducto español en territorio enemigo. Desde esta perspectiva, es posible detectar una transformación en la "ideología de la fortificación" entre el primer y el segundo periodo y, por consiguiente, en el tipo de relación que los españoles mantuvieron con los indígenas. En efecto, el fuerte funcionó primero como enclave en territorio enemigo. Era un espacio protegido, aislado e inexpugnable, que simbolizaba el poder español y real; un lugar estratégico a partir del cual se podían organizar expediciones guerreras para luego volver a encerrarse en él. Funcionaba a la vez como refugio, cabeza de puente en territorio enemigo y marca simbólica de la potencia española sobre un espacio por conquistar. Construir un fuerte venía a significar una presencia y, por consiguiente, un acto de apropiación sobre el territorio comarcano. Se entiende, pues, que la primera tarea de las tropas en su avance progresivo en territorio reche fuera la construcción de reductos fortificados. En definitiva, durante este primer periodo el fuerte cumple únicamente una función guerrera, además de simbolizar un poder; era, sin embargo, un espacio clausurado, que impedía cualquier comunicación con los indios.

Otro tanto ocurre con el camino real, cuya existencia era sobre todo simbólica. Dicho camino, que vinculaba entre sí los diversos asentamientos españoles en territorio enemigo, no tenía como objetivo establecer una 
comunicación con los indios ni mucho menos vigilarlos. Una vez más, el problema de los españoles no era la comunicación con el Otro. El único tipo de contacto que los conquistadores tenían con las comunidades que vivían en los alrededores del fuerte estaba encaminado a cubrir sus necesidades alimenticias, para no morirse de hambre.

\section{La política de guerra defensiva como precursora del diagrama civilizador}

Como ya he señalado en la introducción, este modelo de conquista, que funcionaba a partir de una lógica de integración-exclusión, no era el único en la época. En efecto, en la política de guerra defensiva llevada a cabo por el jesuita Luis de Valdivia (1612-1626) se pueden percibir señales precursoras del modelo de asimilación-marginación que va a imponerse a partir de la segunda mitad del siglo XVII, pues lo que proponía este émulo de José de Acosta era pacificar a los indios por medio de la evangelización, el comercio y la política. Inscrito en la tradición lascasiana de crítica a las exacciones cometidas por los españoles (trabajo personal, esclavitud, guerra a sangre y fuego) y con una gran experiencia misional adquirida en Juli, Valdivia fue el precursor en Chile de una política de comunicación con los indios. En tanto que consideraba la barbarie de los indios como el fruto de la habituación y de la influencia de Satanás, la lucha va a desarrollarse en dos frentes simultáneos: contra el diablo y las prácticas demoníacas y perversas de los reche por un lado y, por el otro, a través de la transformación de sus hábitos culturales y de su organización social.

Si bien el proyecto del jesuita es original en el Chile de principios del siglo XVII, sabemos que se inscribe en un movimiento más general de transformación de la relación con el Otro y de la problemática de la diferencia cultural que se desarrolla en América; un proceso que A. Pagden resume, en la introducción a su estudio sobre los orígenes de la etnología comparada, en estos términos:

...explicar un cambio transcendental en la comprensión de las sociedades humanas, el cambio de las descripciones generalizadas del comportamiento humano en términos de las disposiciones psicológicas individuales a una sociología ética basada en la observación empírica, el cambio de una descripción de las culturas en términos de una naturaleza humana que se consideraba constante en el tiempo y el espacio, a un mayor relativismo antropológico e histórico. En el lenguaje de Michel Foucault, se trataba del 
cambio de un mundo en el que el pensamiento se movía "en el elemento del parecido" en busca de "las figuras restrictivas de lo semejante", a uno en el que los observadores empezaron a registrar, clasificar y describir la diferencia y la discontinuidad. ${ }^{16}$

En la medida en que los errores de los indios estaban determinados por el contexto sociocultural en el que habían sido educados, así como por la lucha que el demonio mantenía contra las criaturas de Dios, pero también en la medida en que su mentalidad era infantil puesto que su mundo cultural era, en comparación con Europa, un mundo nuevo, era posible y necesario educarlos.

Es en este marco ideológico como es preciso entender tanto el significado del proyecto y de los métodos desarrollados por Valdivia como las resistencias que provocó y que pudieron más que la política de guerra defensiva y de evangelización. ¿Qué es lo que planteaba Valdivia? ¿Por qué fracasó su empresa?.

En primer lugar, propone acabar con la conquista por las armas, el trabajo personal y la esclavitud, pues además de entrar en contradicción con los valores más fundamentales del evangelio, son las principales causas de las sublevaciones indígenas. Al mismo tiempo, procura entablar una comunicación con los indios rebeldes, organizando reuniones políticas (parlas) con las comunidades enemigas para transmitir un mensaje de paz. Al igual que el gobernador Alonso de Ribera, planea consolidar una línea fronteriza a lo largo del río Bío-Bío con el fin de oponerse a las malocas de los reche de tierra adentro en territorio pacificado. Existe, sin embargo, una diferencia esencial en la concepción que uno y otro se hacen de la frontera: para Ribera se trata de consolidar las posiciones españolas y de emprender regularmente expediciones guerreras tierra adentro para reducir a los indios y hacer avanzar progresivamente la línea fronteriza; para Valdivia, en cambio, se trata de asegurar una infraestructura sólida de donde puedan partir los misioneros a realizar su tarea evangelizadora.

Por otra parte, las fortificaciones que proyecta instaurar el jesuita ya no son consideradas como lugares aislados e inexpugnables, sino como los eslabones de una cadena de comunicación y vigilancia. En efecto, Valdivia concibe el fuerte como un dispositivo de visibilidad, que permite vigilar y proteger a los indios amigos asentados en sus alrededores. Vigilarlos y además controlarlos, pues una vez reducidos a pueblos en las proximida-

16 Pagden, Anthony: La caída del hombre natural. El indio americano y los orígenes de la etnología comparativa, Madrid, 1988, pág. 21. 
des del fuerte ya no podrán hacer lo que se les antoje. Al mismo tiempo, protegerlos contra las malocas de los indios de tierra adentro, a los que Valdivia llama, y ésta es una novedad discursiva fundamental cuyo alcance se analizará más adelante, ladrones o delincuentes. Además, el fuerte ya no es sólo un lugar-refugio, desde el que se emprenden expediciones militares o misionales, sino también un espacio abierto y permeable hacia el que es necesario atraer a los indios. La línea fronteriza, concebida hasta entonces como una línea defensiva y guerrera, pasa a ser considerada como un espacio de comunicación, que debe servir para establecer contactos, tejer vínculos e informarse de lo que pasa tierra adentro.

En definitiva, la máquina política en la que se inscriben esos nuevos dispositivos de poder (la misión, la reducción a pueblos, la frontera como espacio de comunicación y de vigilancia, la "parla" como reunión política hispano-reche cuyo objetivo es el de informar e informarse) es fundamentalmente diferente a la dominante durante este primer periodo. El proyecto de Valdivia tiene que ver con otro tipo de poder que ya no busca imponer por la fuerza o reprimir, sino más bien incitar, convencer, inducir pautas de comportamiento, transformar las costumbres e instaurar normas o una norma común y homogénea.

Dicho proyecto, además de chocar contra los intereses estrictamente materiales de soldados y encomenderos ${ }^{17}$ se fundamentaba en un principio político radicalmente distinto al entonces imperante. Con Luis de Valdivia se puede afirmar que el Chile colonial entra en la era moderna de la civilización, cuyo medio de acción principal, al menos durante un primer momento, es la evangelización. Por lo tanto, el periodo de guerra defensiva no es un etapa desprovista de significado, como algunas veces se ha dicho, sino que deja aparecer las primeras fisuras del modelo soberano de conquista y prefigura un tipo de saber y una concepción del poder que llegarán a ser dominantes durante el segundo periodo.

Volviendo a la concepción valdiviana de los distintos dispositivos que debían conducir a la pacificación de los indios delincuentes, veamos lo que escribía a propósito de las fortificaciones en la zona de Yumbel:

...habiendo de meter adentro los indios de Cayuhuenu que recibian daño del enemigo, aquel fuerte que solo servia de ampararlos se puso donde hiziesse dos oficios, que

17 Sobre el tema de la centralidad de la guerra en el funcionamiento económico general de Chile en el siglo XVII véanse Jara, Alvaro: Guerre et société au Chili. Essai de sociologie coloniale, París, 1961; Zúñiga, Juan-Pablo: Espagnols d'outre-mer. Émigration, reproduction sociale et mentalités à Santiago-du-Chili au XVIIème siècle, Florencia, Instituto Universitario Europeo, Tesis de Doctorado, 1995. 
los amparasse y en lugar mas seguro y guardasse mucha mas tierra, convirtiendole en los seys torreones que guardan las cinco leguas de Puchangui, donde las postas se ven unas a otras y ven a la posta del campo de Yumbel. Y con sola la gente de Cayuhuanu [sic] se poblaron seis torreones a diez soldados cada uno, y los soldados son mejor visitados alli y alimentados. Y el campo puede presto acudir al socorro, y los indios tienen mejores tierras para sembrar y todos estan debajo de una posta que les esta mirando... Parecio bien fortificar estas cinco leguas con seys torreones de adoves que se ven el uno al otro, y no puede passar de dia nadie sin ser visto... ${ }^{18}$

Las tres ideas claves que resaltan de este texto y que, como sabemos, estructuraban el proyecto valdiviano son: vigilar, civilizar y proteger. ${ }^{19} \mathrm{El}$ poder de vigilancia tal y como él lo concibe ya no busca ser visto de todos, como en el caso del poder soberano que encontraba el principio de su efectuación en la manifestación ostentatoria de su existencia, sino más bien verlo todo. El recinto fortificado es uno de los muchos puntos de visibilidad de una cadena flexible, que tiende a controlar y registrar la multiplicidad de los movimientos. Por otra parte, el desplazamiento de los indígenas no se concibe desde una perspectiva de explotación de la fuerza de trabajo, sino como un medio para su civilización. Hay que vigilar y, si llega el caso, castigar a los indios, pero es preciso también inculcarles nuevos modos de vivir, sin obligarles ni constreñirles mediante la coacción o la fuerza bruta. Es así como se les distribuyen mejores tierras para que se sedentaricen y adopten una actividad económica digna de los verdaderos hombres: la agricultura. Es así también como se les trata de enseñar a que vivan con más policía, juntándolos en pueblos. Por último, hay que protegerlos de la violencia de los indios de tierra adentro. Valdivia espera que esta obra de civilización sirva de ejemplo además a los indios ladrones, atribuyéndole al comercio un importante papel en esa nueva empresa de pacificación:

18 Memorial del Padre Luis de Valdivia, "El Padre Luys de Valdivia Vice-Provincial de la Compañía de Jesús en el Reyno de Chile. Digo que la mayor parte de mi vida, he gastado en la conversión y pacificación del dicho Reyno...", en Archivum Romanum Societatis Iesu (en adelante ARSI), Chilensis Historiae, vol. 4 (1604-1664). La fecha inscrita sobre el documento es 1611; sin embargo, por la naturaleza de los hechos narrados y habida cuenta de que Valdivia señala que hace 29 años que está en Chile, más bien parece datar de comienzos de la década de 1620.

19 Encontramos esta triple exigencia en otro texto de Valdivia cuando escribe: “...los mismos indios del estado de Arauco para estar bien amparados con ocasion del daño que les hiço Anganamon, pidieron reducirse y asi se redujeron a media legua y a una y a dos del fuerte de Arauco de donde nuestro campo los puede amparar mejor..., donde mucho mejor pueden ser enseñados en la fee con menos riesgos de los padres de la compañia que estan en Arauco ... estan mas juntos para defenderse del enemigo y ser defendidos de nosotros y mejor castigados los que dellos delinquieren" ("Relación breve de lo sucedido en la pacificación del Reyno de Chile por los medios que su magestad cometió al Señor Marqués de Montesclaros virrey del Pirú que llevó a su cargo el padre Luys de Valdivia de la Compañía de Jesús desde el 13 de mayo de 1612 hasta 1 de noviembre de 1613 años”. ARSI, Chilensis Historiae, vol. 4, 1604-1664). 
...en quitandoles [a los indios rebeldes] el cebo que hasta aqui han tenido para hacer daño a nuestros amigos antes de las reducciones, y en fortificando nuestra frontera bien por donde hasta aqui hemos experimentado sus entradas, no han de poder entrar sin ser vistos...no han de hallar en que hacernos daño y lo han de recibir de ordinario; esto les necesitara a dejar la guerra y convertir el pillaje en comercio, como ya lo han comenzado a hazer a temporadas. ${ }^{20}$

Reforma de las costumbres, transformación de la organización social y política, extirpación de las falsas creencias, instauración de un nuevo modelo económico y reeducación de los cuerpos (hexis corporal) y de las almas (habitus cultural), todos esos aspectos del proyecto valdiviano en particular, y jesuita en general, muestran que la empresa de evangelización es concebida como una empresa global de civilización.

Otro aspecto a tener en cuenta en esta política es el marquage simbólico del territorio que entrañaba la edificación de capillas y la instalación de cruces. A diferencia del poder real, que simbolizaba su presencia y se apropiaba del espacio mediante las fortificaciones enclavadas en territorio enemigo, los jesuitas utilizarán este otro tipo de marquage, en el que la capilla y la cruz se ubican en el corazón mismo de las comunidades indígenas y se incorporan a las estructuras ya existentes, siendo ambas concebidas como instrumentos de penetración en el tejido sociopolítico indígena. Los misioneros tratan además de adecuarse a las categorías nativas (identifican la cruz con el voye, árbol de canelo con valor sagrado para los reche; no vacilan en hacerse pasar por chamanes o, al menos, no despejan las dudas sobre su identidad real...) e intentan insertarse por este medio en el tejido social mapuche con el fin de conocerlo y actuar sobre él. El tipo de saber que los jesuitas elaboran y desarrollan sobre el ser social indígena está íntimamente relacionado con la naturaleza del poder que buscan ejercer sobre un sujeto (individual y colectivo) desde ahora bastante bien conocido y definido.

Es así como, durante el parlamento de Catiray (1612), Valdivia no duda en adoptar el ritual tradicional reche: se deja conducir al lugar que ellos reservan para sus cojau (reuniones políticas), penetra en este terreno sagrado con una rama de canelo en la mano (tal y como prescribe el rito), se dirige a los indios en mapudungun y sigue el orden de precedencia que impone el admapu (costumbres de la tierra o tradición). En fin, da muestras de una apertura poco común en su época e inaugura un nuevo tipo de relación con el Otro.

20 Ibídem. 
Ahora bien, no hay que equivocarse y cometer el anacronismo de considerar a los misioneros como unos defensores respetuosos de la cultura y del modo de vida indígena. Los jesuitas mantienen una auténtica guerra. Son los soldados de Cristo contra Satán y no vacilan en oponerse a unas prácticas bárbaras que, como hemos visto, no parecían molestar demasiado a sus coetáneos (encomenderos, soldados, oficiales y gobernadores). Durante su misión en la isla de Santa María, por ejemplo, los jesuitas se opusieron a la realización de un rehuetun, que las autoridades civiles no habían juzgado necesario prohibir:

Un cacique en nombre de toda la isla tomo la mano y dijo... que assi como nosotros teniamos nuestro dios, nuestra ley y nuestras ceremonias en la misa, asi ellos tenian su dios, que era el guecubu y a el adoraban, tenian las tradiciones de sus antepasados, que era su ley, y sus sacerdotes y ceremonias, y que havian de hacer la fiesta de reguetun donde habian de elegir sus sacerdotes, y asi, que nos podiamos ir porque no havia lugar para oir las cosas de dios... le dijo el Padre Aranda que mirase bien lo que habia dicho, que por ser cristiano merecia mui grande castigo. Entonces, otro cacique llamado don Pedro Lebeuya quiso dorar lo que el otro tan desvergonzadamente dijo, diciendo que en el reguetun no adoraban al guecubu ni al demonio, mas solamente trataban de cosas pertenecientes al gobierno y daban a entender a las mugeres que el guecubu les descubria sus maldades para que viviesen bien. Mas en realidad, de verdad comunmente dicen que en este reguetun hablan con el demonio y hasen otras mil supersticiones. Empezaron su reguetun, no se atreviendo el corregidor a quitarselo por haverles dado el señor gobernador licencia para ello. ${ }^{21}$

Hay que señalar que con los jesuitas entramos en una etapa de proliferación de relaciones e informes que tratan de la sociedad reche desde el punto de vista político, religioso y económico. Además se emplea un nuevo tipo de vocabulario, donde los indios no-reducidos ya no son rebeldes, sino ladrones y delincuentes. El encarcelamiento o el cautiverio ya no son concebidos como una manera de afirmar el poder real, sino como una labor de reeducación. Los jesuitas hacen listas de los miembros de las comunidades que visitan, establecen clases y categorías de indios y proceden mediante una lógica de individualización. Como en el caso de la disciplina estudiado por Foucault, la civilización "fabrica" individuos. Se trata de una técnica específica de poder que "toma a los individuos a la vez como objetos y como instrumentos de su ejercicio" ${ }^{22}$. El tipo de saber que desarrollan

21 "Carta anua de la Provincia de Paraguay, Chile y Tucumán” (1609). ARSI, Provincia Paraquariae, vol. 8, Annuae 1608-1649.

22 Véase Ewald, François: "Michel Foucault et la norme", en Giard: Michel Foucault..., pág. 206. 
los misioneros corresponde a un tipo de poder que busca disciplinar, normalizar, civilizar. Se adquiere información para actuar con más eficacia y con el fin de extender, intensificar e incrementar los efectos del poder. Ya no se constriñe, prohibe, reprime o impide, sino que se utiliza el conocimiento acumulado y cuidadosamente clasificado para producir, incitar, inducir, intensificar. Se procura inmiscuirse en la sociedad indígena, crear lazos de dependencia reales o simbólicos y multiplicar las relaciones diádicas. A menudo se recurre a las artimañas y se emplea la ambigüedad, el artificio, el simulacro o el "engaño honesto" para que los indios se vuelvan virtuosos. ${ }^{23} \mathrm{Se}$ intenta establecer un nuevo tipo de saber-poder, que es preciso rastrear en los micro-actos que obligan e incitan de manera casi imperceptible. Es en el detalle y a través de minucias cómo actúan los misioneros y es por la multiplicación de esos pequeños pormenores cómo nace la empresa más amplia y eficaz de vigilancia y de sujeción de los indios. Y si bien es cierto que esta microfísica de la civilización fracasa durante el primer periodo, a partir de la segunda mitad del siglo XVII la lógica de la civilización se va a imponer como la forma dominante y como el principio ordenador de una nueva máquina de pacificación.

\section{El poder civilizador como nuevo principio de sujeción: evangelización, política y comercio (1641-1810)}

Como bien ha señalado Rolf Foerster, el parlamento y la misión fueron los dos mayores "logros" de la obra evangelizadora jesuita. ${ }^{24}$ Los soldados de Cristo tuvieron, en efecto, un papel fundamental en este segundo periodo. Primero, porque fueron los que soportaron casi todo el peso de la empresa misional en las zonas fronterizas y tierra adentro. Segundo, porque su conocimiento de la realidad sociocultural indígena y sus métodos de penetración fueron de gran utilidad en la construcción de un nuevo espacio de discusión y confrontación: el parlamento. Por lo tanto, los jesuitas se ubicaron en el centro de las dos instituciones que iban a imponerse como los pilares de la nueva política española en tierra araucana.

23 Sobre el tema de la disociación machiaveliana entre la acción política y la moral así como sobre la distinción entre el ser y el parecer en el arte de gobernar véase Senellart, Michel: Les arts de gouverner. Du regimen mediéval au concept de gouvernement, París, 1995. Senellart utiliza la expresión honnête tromperie.

24 Foerster, Rolf: Jesuitas y mapuches, 1593-1767, Santiago de Chile, 1996, pág. 371. 
Conviene, pues, interrogarse sobre la naturaleza de tales instituciones y sobre el tipo de relación que tienden a establecer con el Otro. Muy a menudo han sido consideradas como espacios de convivencia, de paz, de consenso o de pacto, como si toda voluntad de sujeción estuviera ausente y nos encontráramos ante unos espacios encantados de la libre comunicación. Sin embargo, tanto el parlamento como la misión (junto con las escuelas de indios, la institución de los caciques embajadores, el establecimiento de puestos fronterizos, la regulación del comercio a través de la organización de ferias y de la creación de licencias, etc.) se dibujan como dispositivos de normalización, cuyas principales preocupaciones son el orden público, la policía y la institucionalización de una norma jurídicopolítica común.

No voy a analizar aquí la lógica misional en sí, ya definida al presentar el proyecto de Valdivia. Lo que trataré de demostrar, a través del estudio de los parlamentos, es que los principios políticos desarrollados por los jesuitas a principios del siglo XVII (vigilancia permanente, normalización, individualización, centralización, comunicación, información) constituyeron la base sobre la que se construyó la nueva empresa civilizadora llevada a cabo hasta, por lo menos, su expulsión.

Según la historiografía tradicional, 1641 marca un hito en la política española hacia los mapuche. Es, en efecto, en este año cuando el gobernador Francisco López de Zúñiga entabla una política de parlamento, que tiene como meta establecer la paz sobre nuevas bases. Es también entonces cuando, con motivo de los parlamentos de Quillín, Repocura e Imperial, se reconoce la frontera del Bío-Bío como línea de demarcación entre dos mundos: el indígena al sur y el español al norte. No hay que engañarse, sin embargo, sobre el significado de esta frontera, puesto que las autoridades españolas reconocen a los nuevos vasallos del rey el derecho a disfrutar libremente de sus tierras en la medida en que, precisamente, aceptan ser y comportarse como súbditos. Esto conlleva una serie de obligaciones y supone el cumplimiento de un cierto número de compromisos por parte de las comunidades que han aceptado los nuevos términos de la comunicación. Todo esto no quiere decir que la citada fecha no sea importante; se podría incluso afirmar que, quince años después del intento fallido de guerra defensiva, los parlamentos realizados por el Marqués de Baides constituyen el punto de inflexión de la política española en la Araucanía. En efecto, tanto en sus aspectos formales como en sus contenidos dichos parlamentos marcan una ruptura respecto a la política del primer periodo. 
Si nos atenemos al aspecto formal de las relaciones mantenidas por los dos protagonistas durante esas reuniones, percibimos en López de Zúñiga una apertura que recuerda a la de Valdivia. El gobernador, al igual que hizo el jesuita en Catiray, acepta participar en el ritual de paz autóctono. Deja que los ulmenes o caciques sacrifiquen rehueque (llamas) y no interviene en las ceremonias que se realizan entre indios rebeldes y amigos. Recibe de buen grado de manos de los indios la rama de canelo, untada con la sangre del rehueque, y permite que se expresen larga y libremente los representantes de las comunidades. El ritual es respetado en la medida en que, como escribía el jesuita Alonso de Ovalle, esta ceremonia "aunque gentílica parece tiene su fundamento en muchas historias y aun en las sagradas no le falta". ${ }^{25}$

La novedad de los métodos empleados se percibe asimismo en el tipo de relación de poder que el gobernador intenta instaurar. Ya no se trata de imponer o de reprimir, sino más bien de sugerir, manipular e incitar. López de Zúñiga entrega bastones de mando a los caciques, ofrece numerosos regalos y asigna títulos y grados correspondientes a la jerarquía militar española:

Y para honrarlos dio baston con casquillos de plata de gobernador y Capitan general a Lincopichon, por aver sido el primero en dar la paz, y otro de Maestro de campo a Don Antonio Chicaguala y otro de Sargento Mayor al hixo mayor de Lincopichon, Cheuquenecul, para que gobernassen sus tropas contra los que no quisiessen admitir la paz. Mandolos vestir a lo español, con capas y capotillos, y hazer buen agasaxo... ${ }^{26}$

Esta voluntad de sustituir la jerarquía militar reche por una terminología y una estructura española es totalmente original en el Chile de la época. Se puede incluso ver en ello un signo precursor de la política que buscará reducir progresivamente la distancia o diferencia sociocultural con el fin de obtener una paz segura y duradera. Asimismo, en el hecho de vestir a los caciques a la española se puede entrever una anticipación de la política asimilacionista que se va a desarrollar a lo largo de este periodo. Otras propuestas españolas confirman la impresión no solo de una toma de conciencia de la diferencia cultural, entre civilizados por un lado y salvajes por el otro, sino también de su integración como parámetro en la nueva estrategia de pacificación. En efecto, la integración de esa diferencia como ele-

25 "Relación verdadera de las pazes que capituló con el araucano rebelado el Marqués de Baides...en la jornada que hizo para este efecto el año pasado de 1641". ARSI, Chilensis Historiae, Vol. 4, 1604-1664.

26 Rosales: Historia general..., vol. 2, págs. 1137-1138. 
mento a tomar en cuenta en el cálculo político se percibe en la proposición hecha a los indios de entregar a sus hijos para que sean educados en un medio español. ${ }^{27}$

La originalidad de las propuestas del Marqués de Baides radica sobre todo en la utilización novedosa que hace de los religiosos y de la institución misional. Así, en el discurso de los jesuitas que acompañan y aconsejan al gobernador se puede constatar que la evangelización ya no funciona como justificación o codificación de un discurso político de soberanía, sino como principio político en sí. De tal manera que la evangelización acaba siendo el arquetipo de un nuevo tipo de poder que se va asentando poco a poco, y la pacificación de los indios pasa por la construcción progresiva de una unidad en la fe, sinónimo ella misma de uniformización en los modos de vida; pues como señala Diego de Rosales, refiriéndose a las palabras del propio gobernador:

No pretende el Rey ni quiere vuestros hixos, vuestras mugeres, vuestras haziendas, vuestro oro. Su principal deseo y su primer motivo en las conquistas de las Indias y de estas Provincias es la salvacion de vuestras almas, vuestro aumento y quietud. Pues sois hombres racionales y conoceis el bien y el mal y el discurso natural y la experiencia os lo ha dado a conozer, dexad de veras y de todo corazon vuestra porfia, vuestras traiciones y dobleces. Tened lastima a vuestras almas, a vuestras vidas y a vuestra libertad; hazeos cristianos y tengamos un corazon y una fee; que [a] menos de que lo seais, no podemos tener union verdadera; porque no ay union entre las naciones si no es por la Religion, y lo que las divide es la diversidad de la creencia y adoracion... Aumentad vuestros ganados y no deis de comer con ellos al enemigo, lograd el trabaxo de las sementeras; que mexor que las coma quien con sudor las haze, que no que se las coma el fuego, que las consume sin provecho. ${ }^{28}$

Como se puede ver, ya no se trata de extraer un tributo, sino de procurar que los indios se vuelvan a instalar en sus tierras para que produzcan; se les incita a trabajar, a producir y a multiplicarse. Ya no se les amenaza con la muerte, sino que se intenta regular su vida. Todos esos puntos están presentes en las condiciones de paz aceptadas en Quillín y que Rosales resume de esta manera:

Primera: que todos los Caciques e indios retirados han de salir de los montes, donde se hazian fuertes, y poblar los llanos y los valles, donde vivan en vida politica y no como salvages en las selvas. La segunda, que todos los Caciques han de obligar a

27 Véase "Relación de lo subcedido en la jornada q. el Sr. Marqués de Baydes, Gobernador y Capitán general de este reino de Chile y Pressidente de la Real Audiencia hiço a tierras de los enemigos", reproducido por Lázaro Avila: La transformación sociopolítica..., págs. 319-336.

28 Rosales: Historia general..., vol. 2, pág. 1132. 
todos los Indios retirados, de la tierra adentro, a que se vuelvan a sus tierras antiguas de sus Padres y antepassados con sus familias y ganados, sin que los pueda detener pariente ni otra comodidad. Y los que de sus tierras quisieren venir a poblar a las de los españoles o Indios amigos, se les ha de dexar a su voluntad, con sus mugeres, hijos y haziendas... La sexta, que han de admitir predicadores y ministros de el Evangelio, para que los prediquen y industrien en el conocimiento de el verdadero Dios. ${ }^{29}$

Esta voluntad de civilizar a los indios mediante la sedentarización, la transformación de su mentalidad económica, la producción disciplinada y sin despilfarro, la instauración de una norma religiosa y, por lo tanto, cultural y de un control permanente sobre sus cuerpos y actividades, la volvemos a encontrar unas décadas después en los acuerdos firmados en el parlamento de Malleco (1671):

1. ...han de salir de las montañas en que se hallan y venirse a vivir a sus poblaciones antiguas conforme estaban antes del alçamiento; 2. ...han de estar unidos en sus rancherias para que puedan los curas y padres misioneros instruirlos en los misterios de nuestra santa fe; 3 . An de estar con un Capitan de Amigos en su poblacion para que los mantenga en paz y justicia rija y govierne para todo lo que se ofreciere del servicio de su Magestad...; 4. An de estar obligados a asistir a todas las escoltas y conducirlas a los fuertes y partes donde mas combenga resultando en esto la combeniencia propria y suya en que no esten ociosos y que tengan algun exercicio... 6. Que todos los indios sean restituidos en sus haciendas para que las cultiven y usen de ellas como proprias quedando obligados a sembrarlas para que con este exercicio se baian enseñando a vida politica y sociable y que cada mes nombren un cacique que venga a darme quenta de la forma y [?] en que se allan y ynformarme de los agravios y bejaciones que recivieren de otros yndios o españoles para que se probea el remedio que mas convenga en justicia mantendiendolos en ella; 7. Que siempre que hubiesen de salir de su poblacion para otra que an de dar quenta a su Capitan de Amigos para yr y bolber limitandoles el tiempo; 8. Que todos los cautivos sean restituidos y que si hicieren fuga en algun tiempo de sus poblaciones a otras den quenta al Capitan de Amigos para que los restituya a sus encomenderos; 10. Que qualesquiera Caciques que en tiempo de guerra ayan maloqueado a otros caciques se restituian las pieças que ubieren apresado tanto de una parte como de otra olvidando rencores y viviendo con quietud y paz amigable. ${ }^{30}$

Observamos aquí una nueva etapa en el proceso de vigilancia y cómo los nuevos mecanismos de poder empiezan a ser enunciados de manera relativamente clara. El capitán de amigos cumple ahora un doble papel. En primer lugar, debe actuar en sustitución de los mecanismos indígenas para

29 Ibídem, pág. 1136.

30 "Artículos que han de observar y guardar en lo de adelante los caciques y parcialidades que han venido a dar la obediencia a Su Majestad...” (Paraje y campaña de Malleco, 10-01-1671, Don Juan Henríquez). Archivo General de Indias (en adelante AGI), Chile, 62. 
regular los conflictos. Se pretende de este modo no sólo el control y la neutralización de la legislación criminal autóctona, sino también el hacer reinar una paz y una justicia definidas a partir de criterios jurídicos españoles y extracomunitarios. Ahora bien, ese marco jurídico-político exógeno no debe imponerse desde el exterior por medio del suplicio y la coacción; lo que se busca es establecer una relación de poder particular e interna entre el capitán de amigos y los miembros de la comunidad. Aparece entonces la voluntad de reemplazar los mecanismos reguladores indígenas por nuevas técnicas que ya no pasan por la compensación o la muerte, sino por el castigo. El delincuente debe ser castigado en la medida en que viola la paz púbica y atenta contra la soberanía de la comunidad en particular y contra el orden colonial en general.

El segundo papel que debe desempeñar el capitán de amigos es el de capataz o vigilante de la comunidad; no sólo ha de controlar un espacio concreto sino también el tiempo de quienes lo habitan. La civilización de los indios pasa por el control de su espacio y de su tiempo, y por la inculcación de un arbitrario cultural que considera que el tiempo es precioso y que el espacio está hecho de segmentos. El capitán de amigos tiene la difícil misión de inducir a los indios a que vivan con más policía, mediante el ejercicio de un poder de vigilancia que funciona de manera continua y exhaustiva.

Otro aspecto interesante y novedoso del parlamento de Malleco es la incitación que se hace a los indios para que produzcan, aconsejándoles que trabajen sus tierras para así aprender poco a poco a vivir con más policía y reducirse a una vida sociable. Se les pide además que den cuenta regularmente del estado de la producción agrícola. Esta voluntad de transformar la mentalidad económica indígena se expresa muy claramente por medio de una nueva dicotomía: indios trabajadores frente a indios ociosos.

El parlamento que tuvo lugar en Yumbel unos años más tarde (1692) constituye otra importante etapa en la instauración de este nuevo diagrama civilizador-asimilador. Tal y como señala Leonardo León, el discurso de las autoridades españolas, y especialmente el del gobernador Marín de Poveda, ya no se basa en las amenazas. ${ }^{31}$ El objetivo primordial del gobernador es el de mostrar que la paz es posible con tal de que los mapuche adopten poco a poco los usos y costumbres de los españoles, siendo la conversión el principal medio en esta empresa civilizadora. Como en el parlamento de Quillín, la paz es posible en la medida en que se logre establecer una uni-

31 León Solis, Leonardo: "El pacto colonial hispano-araucano y el Parlamento de 1692". Nütram, 30, Santiago de Chile, 1992. 
dad en la fe, entendida como uniformidad en los modos de vida. Como bien dice un cacique mapuche hispanizado, presente en el parlamento, se trata de "hacer nuevo mundo en el modo de vivir reformando los ritos y las costumbres de la ley ignorante en que vivían los indios". ${ }^{32}$

Marín de Poveda promete a los mapuche no extraer más tributo y procurar además que no se realicen más malocas y expediciones militares en su territorio. Ellos, a su vez, deben corresponder como "...vasallos y procurar de su parte seguir y imitar las costumbres y modo de bivir de los españoles". ${ }^{33}$ También deben limitar las guerras intestinas, plegarse a una nueva relación económica (el trabajo asalariado en las estancias fronterizas), aceptar la intromisión de los capitanes de amigos en sus asuntos internos y abrirse en cuerpo y alma a la labor de reforma ontológica y sociocultural puesta en marcha por los misioneros. La nueva política de Marín de Poveda tiene como meta matar al indio que hay en el hombre para que sea verdaderamente hombre. Sin embargo, esta empresa humanista y etnocida no debe llevarse a cabo por la fuerza. La idea es llegar a asimilar a los indios a la sociedad, a la cultura y a la máquina productiva hispano-criolla a través de un largo y minucioso proceso de deculturación y de normalización de los espacios. En este contexto, la noción de frontera adquiere un sentido radicalmente nuevo: la frontera del Bío-Bío ya no es concebida como una línea guerrera, sino como un espacio-tiempo de civilización, como una zona de transición entre la barbarie y la civilización. Se aspira a que este espacio se vaya dilatando a la vez que la diferencia sociocultural se vaya retrayendo.

El parlamento se convierte en una institución central de esta nueva política de regulación e imposición de una norma jurídico-política común. Así, en los parlamentos de Negrete (1726) y Tapihue (1738) se intenta regular y vigilar las relaciones económicas hispano-indígenas mediante la implantación de un sistema de ferias, la necesidad de un permiso para cruzar la frontera (en ambas direcciones) y la delimitación de los productos que se pueden o no vender; además, los oficiales de los puestos fronterizos deben vigilar los desplazamientos, controlar los precios de venta y registrar las cantidades de objetos intercambiados.

Otro de los aspectos fundamentales en las actas de estos parlamentos radica en la voluntad de responsabilizar al cacique en caso de violación de los acuerdos. Esta disposición jurídica es, en mi opinión, una pieza central

32 Citado en ibídem, pág. 45. 
en el asentamiento de esta nueva máquina de poder. En efecto, mediante esta responsabilización individual del cacique lo que se busca es: 1) crear cabecillas y actuar sobre el edificio sociopolítico indígena en el sentido de una mayor centralización; 2) establecer un espacio común con una única norma jurídico-política, que funcione tanto del lado indígena como del lado hispano-criollo; 3) generar y crear individualidades o individuos positivos que actúen en el sentido deseado, no por temor o en respuesta a una coacción exterior sino por interés y necesidad interna, debido a la posición que se ocupa en el nuevo campo de poder y a la interiorización de nuevas normas de conducta y de nuevos valores.

De ahí que los tres aspectos recurrentes y notables de esta nueva máquina de civilización-asimilación-normalización sean: 1) la tendencia a la concentración de la estructura sociopolítica de los grupos o sociedades sobre los que se intenta actuar; 2) el énfasis puesto en la producción de individuos responsables de sus actos y de los de sus sujetos así como de individualidades positivas, con el fin de aumentar los efectos del poder; 3) la búsqueda de la uniformización y homogeneización cultural a través de la inculcación-interiorización de valores, ideas, pautas de comportamiento, representaciones del cuerpo, etc., etc. Todos estos aspectos (económicos, políticos y civiles) los encontramos confirmados y resumidos en los acuerdos correspondientes al parlamento de Tapihue (1774):

...les propuse y aceptaron el nombramiento de jueces... para que celasen de las salidas de los mocetones y las entradas de yanaconas, españoles, mulatos y negros, con obligación de dar aviso al cacique para su inmediata expulsion y remesa a los comandantes de las plazas cercanas como para el castigo de los que saliesen sin licencia y facil averiguacion de las especies, ganados y animales que llevasen robados, haciendose de lo contrario responsable el cacique que los permite o disimulase o no procediese a la restitucion... Que no han de usar [los indios] de otros pasos del rio Bio Bio que los que tengo señalados, presentandose a los cabos de las plazas que los resguardan, con manifestacion de los efectos que sacaren de sus tierras y de los que retornasen con sus productos o de los que adquerieren con su trabajo personal en haciendas españolas... Ofrecieron ultimamente entregar sus hijos para su educacion politica y christiana en colegios. ${ }^{34}$

Por otra parte, hay que añadir que los españoles aprovecharon este parlamento para reafirmar una vez más su voluntad de injerencia en los asuntos inter-mapuche: el gobernador Jáuregui pidió a los indígenas que acabasen con sus luchas internas para no perturbar el orden y el bien público.

33 Ibídem, pág. 28.

34 Biblioteca Nacional de Chile (en adelante BNC), Manuscritos Medina, vol. 192, doc. 4491. 
En el parlamento de Tapihue se pone muy bien de manifiesto que estamos ante un dispositivo que intenta actuar de manera exhaustiva y cuya función es la transformación de las costumbres y las formas de organización sociopolítica indígena. A lo ya dicho, hay que sumar otras dos facetas. En primer lugar, el deseo de hacer que esas reuniones sean lo más generales posibles y que cada comunidad allí representada encuentre su lugar en un espacio desde ahora ordenado y clasificado de manera rígida; en segundo lugar, la denominación de unos representantes indígenas que debían vivir de manera permanente en Santiago, los llamados caciques gobernadores.

Con la creación de esta institución se pretendía instalar en la ciudad a representantes de los cuatro futamapu que pudieran comprometer con sus decisiones a la totalidad de las comunidades indígenas. Era una idea completamente subversiva y un dispositivo de un marcado carácter aculturador en la medida en que intentaba romper con el sistema político indígena, en el que las decisiones se tomaban colectivamente a través de una confrontación directa de todas las opiniones existentes. He aquí un texto que describe de manera bastante nítida lo que los hispano-criollos se proponían lograr mediante esta disposición jurídico-política, en la que se refleja de nuevo la voluntad de normalizar-civilizar-centralizar:

...se llevo a efecto por Augustin Jauregui, siendo Capitan General de este reino i frontera, el conducir i tener de residencia fija en la capital de Santiago algunos de los principales caciques en calidad de embajadores, para que por ellos se representase al jefe lo oportuno para su gobierno i ellos mismos, aleccionados con el gobierno i politica de los españoles, no solo se civilizasen sino tambien se instruyesen i fuesen capaces de instruir los suyos; tuvose tambien la mira a tener estas cabezas como en rehenes, para cautelar i precaver los insultos i hostilidades de sus facciones, i con los mismos fines se establecio del ramo de temporalidades un colegio en que pusieron los hijos de algunos caciques. ${ }^{35}$

El último punto que considero importante destacar de los acuerdos firmados en Tapihue tiene que ver con la voluntad española de imponer un nuevo marco jurídico a los grupos indígenas de tierra adentro y de traspasar las prerrogativas penales desde el interior de las comunidades hacia el exterior. El cacique es desde ahora el responsable de los actos delictivos que se cometen en el seno de su comunidad, debiendo entregar a todos los

35 "Relación de las misiones del Obispado de Concepción de Chile del Obispo al Rey" (28-08-1784). BNC, Manuscritos Medina, vol. 202, doc. 4998. 
delincuentes (indios, criollos, mulatos, mestizos) a las autoridades españolas. Unas medidas que demuestran la intención de fortalecer el poder de los caciques, a la vez que reflejan una de las características principales de esta nueva máquina de poder, que busca sobre todo individualizar e imponer unas normas. En consonancia con ello, ya no se define el malón como una empresa bélica sino como un delito; a los conas ya no se les considera como guerreros ni a sus caciques como jefes de guerra, sino que se les incluye en la categoría genérica de delincuentes, junto con los vagabundos y bandidos mestizos o mulatos. De tal manera que se podría decir que es a través de esta nueva gestión de la ilegalidad y en función de la instauración de un tipo particular de poder cómo se va dibujando la nueva figura del delincuente y se construye la categoría de la delincuencia, entendida ésta como un acto que perturba el orden público colonial y obstaculiza la empresa de pacificación-civilización.

Definidas las normas de vida (parlamento de Yumbel), corresponde ahora definir normas jurídicas y políticas. El espacio social tiende así a homogeneizarse. La diferencia entre el rebelde mapuche y el bandido mestizo ya no es una diferencia de naturaleza; ambos son delincuentes a los que es preciso castigar. $\mathrm{Ni}$ tan siquiera las luchas intermapuche son consideradas como conflictos intertribales, sino como asuntos que conciernen directamente a las autoridades españolas. Asistimos así, durante esta segunda mitad del siglo XVIII, a una auténtica "estatificación" de los mecanismos disciplinarios.

Uno de los medios empleados por las autoridades coloniales para optimizar los efectos de este nuevo poder fue, precisamente, hacer de los caciques verdaderos agentes (en el sentido de juez y policía) del rey. A manera de ilustración veamos lo que dice el decimocuarto punto del parlamento de Tapihue al respecto:

Que para que puedan castigar los delincuentes y malévolos de sus reducciones y hacer justicia a los que la necesitaren o pidieren, acuerden si les parece a exemplo de lo que hacen los españoles a hacer también nombramiento de Alcaldes o Jueces de sus Reducciones..., recayendo los nombramientos en Yndios Nobles de los de mejor opinion, capacidad y juicio, a que han de estar sujetos, siendo a todos superior el Cacique del distrito, y este obligado a hacer que sean respetados y obedecidos los tales Alcaldes o Jueces que nombrare... castigando a los que hicieren perjuicios o no viviesen como deben, ni guardasen los tratados pactados en los Parlamentos, de que han de dar cuenta a su cacique, como tambien de los que se ausenten y pasasen por pasos extraviados del rio Bio Bio, o para las Pampas o haciendas de Buenos Ayres, para que le hagan prender y remitan al Superior 
Gobierno... pues ninguno ha de poder pasar desde ahora el expresado rio, sino por los referidos pasos de Santa Barbara, Puren, Nacimiento, Santa Juana y San Pedro presentandose primero...para que los asienten en el libro que han de tener a esse fin los comandantes...; pues lo mismo se mandara por bando con gravissimas penas contra los españoles que fuesen osados a pasar a sus tierras por otros pasos y sin expresa licencia del Superior Gobierno o del Maestro de Campo General, a los que podran ellos prender y remitirme para que yo los castigue como a transgresores de mis ordenes. ${ }^{36}$

Para terminar esta revisión de las estrategias de sujeción puestas en juego en la construcción de lo que fue un imponente edificio jurídico-político, trataré brevemente algunos aspectos de la política entablada por el gobernador Ambrosio O'Higgins. Si hubiera que resumir la acción de este gran conocedor de la frontera y de los asuntos indígenas, diríamos - retomando una fórmula de François Ewald - que con él pasamos de una civilización-bloqueo a una civilización-mecanismo. ${ }^{37}$ Dicho de otra manera, el objetivo de O'Higgins, figura central en la política fronteriza, no fue el de cerrar los espacios, sino el de abrir vías de comunicación; no el de restringir y vigilar el comercio hispano-indígena, sino el de dejarlo libre. La perspectiva espacial de O’Higgins era mucho más amplia que la de sus predecesores y no toma sólo en cuenta la frontera del Bío-Bío; por el contrario, desea trazar vías de comunicación, seguras y rápidas, entre las fronteras norte y sur del territorio mapuche (Concepción-Valdivia-Osorno-Chiloé) y facilitar las comunicaciones este-oeste (Santiago-Mendoza-Buenos Aires). En definitiva, lo que él pretende es la construcción de un espacio de la perfecta comunicación, un espacio liso, sin segregación.

Los medios utilizados se ponen muy bien de manifiesto durante los preparativos del parlamento de Negrete. Primero, se pone en contacto directo y personal con los caciques con el fin de impulsarles a que actúen en un determinado sentido. En sus cartas emplea un estilo metafórico, en consonancia con la manera de expresarse de los indígenas; trata de comprometerlos moralmente y de darle una profundidad histórica a sus negociaciones, advirtiéndoles que el parlamento es una ceremonia que forma parte de su tradición (admapu) y que deben ser amigos de los españoles porque sus padres también lo fueron. Segundo, les pide que pongan fin a sus luchas intestinas y que dejen transitar a sus enemigos por sus tierras,

36 Citado por León Solis, Leonardo: “El parlamento de Tapihue, 1774”. Nütram, 32, Santiago de Chile, 1993, págs. 39-40.

37 Ewald: "Michel Foucault...", 1992. 
para que puedan acudir al parlamento y no puedan justificar su ausencia en razón de la hostilidad de sus "hermanos de raza".

Asimismo, durante el propio parlamento (1793) negocia con los pehuenche de la cordillera el tránsito regular y masivo de caravanas españolas por los pasos de Antuco y Villacura en busca de la sal ultracordillerana. Conversa con los caciques de la zona de Valdivia sobre la reconstrucción de la ciudad de Osorno, destruida a consecuencia de la gran sublevación de las postrimerías del siglo XVI. Pide a los caciques llanistas que impidan la salida de sus conas hacia las Pampas y la frontera de Buenos Aires. Decide además poner fin a los múltiples tratados que regulan el comercio e indica a los caciques que su autorización para atravesar su territorio ya no será necesaria.

La política de O'Higgins tiene como meta la total homogeneización del espacio sociopolítico de la Araucanía. ${ }^{38} \mathrm{El}$ aspecto más interesante y novedoso de sus gestiones en los asuntos indígenas y fronterizos es el énfasis que pone en la noción de libertad y su convicción de que la civilización de los indios será la consecuencia lógica de la eliminación de las trabas que obstaculizaban la comunicación entre las dos naciones. Ahora bien, la libertad que propone O'Higgins es una libertad vigilada y hay que inscribirla e interpretarla dentro de un proyecto más global de conquista y colonización. En efecto, esas vías de comunicación que se trazan, esos caminos que se balizan y esas trabas que se eliminan son otros tantos dispositivos que permiten establecer unas relaciones de poder determinadas, que deben desplegar su eficacia en ausencia de la figura del rey. La instauración de una libertad vigilada permite a los caciques desplazarse, pero en el sentido indicado. El comercio libre es concebido como un modo de acabar de una vez por todas con el irreductible salvajismo de los salvajes. No hay que prohibir el comercio de vino, puesto que los indios apetecen tanto esta bebida que se puede esperar, a medio plazo, invertir los flujos de bienes $\mathrm{y}$ hacer que los indios borrachos vendan hasta sus caballos. ${ }^{39}$

Con el gobierno de O'Higgins, el Chile colonial-fronterizo entra en otra etapa (laicizada, contractual y jurídica) de lo que podríamos llamar el proceso de civilización. De hecho, la obra misional que había dado su tono

38 Véase al respecto los artículos dos, cuatro y cinco del "Auto del parlamento de Negrete de marzo de 1793". AGI, Estado, 85, no. 7.

39 "El Capitán General O’Higgins da cuenta de los insultos cometidos por los indios de la jurisdicción de Valdivia, del parlamento celebrado y providencias que ha tomado" (12-12-1793). BNC, Manuscritos Medina, vol. 206, doc. 5145. 
al diagrama civilizador durante casi siglo y medio es relegada a un segundo plano. ${ }^{40} \mathrm{~A}$ pesar de ello, la lógica de sujeción de los primeros parlamentos de la segunda mitad del siglo XVII y la de los últimos del periodo colonial es la misma: una lógica de imposición de normas y civilización. Civilización entendida como una nueva anatomía política, humanista, que se despliega como un arte de la distribución de los cuerpos en el espacio a través de un control permanente de las actividades y que se arraiga y efectúa mediante la creación de pequeñas individualidades positivas, adaptadas y funcionales ${ }^{41}$ Normalización que opera a través de la inculcación de un arbitrario cultural, que tiene como meta la asimilación y que, por lo tanto, tiende a generar márgenes y a dibujar nuevas figuras de la alteridad en las fronteras (los delincuentes, los salvajes, los indios ecuestres, los indios ociosos, etc.). ${ }^{42}$

40 Bajo el gobierno de O’Higgins la práctica y el discurso políticos en torno a los indígenas empezaron a independizarse de la esfera religiosa, en la que habían encontrado su principio ideológico hasta ese momento. En su política de pacificación de la zona de Valdivia y Osorno, O’Higgins prefirió contar con la creación de ciudades antes que con el establecimiento de misiones, guiado por el principio de que era imposible introducir la religión si no se había instaurado previamente la civilidad (véase "Carta de O’Higgins a Diego Gardoqui" (8-01-1793). BNC, Manuscritos Medina, vol. 210, doc. 5290). Volveremos a encontrar esa autonomía de lo político bajo el gobierno de Muñoz de Guzmán, a principios del siglo XIX. Así, durante la realización del parlamento de Negrete (1803), ya no se trata la brujería como un problema religioso sino como un asunto eminentemente político. El discurso de Pedro Quijada, que presidió el parlamento, no hace ninguna referencia a la empresa evangelizadora e insiste sobre las ventajas políticas y económicas de una comunicación pacífica entre españoles y mapuche (véase "Extracto de las actas y de los tratados de amistad que se renovaron en el Parlamento general celebrado con los Yndios... en los días 3, 4 y 5 de marzo de 1803". Archivo Nacional de Chile, Fondo Morla Vicuña, vol. 24, fs. 108-123). Sobre la progresiva laicización del proyecto de civilización en América y la influencia de la Ilustración véase Duchet, Michèle: "De la destruction des indiens à la civilisation des sauvages: une thématique de l'idée coloniale au XVIIIème siècle", en Jaulin, Robert (comp.): Le livre blanc de l'ethnocide en Amérique, París, 1970, págs. 227-272.

41 Retomamos aquí un formulación de Frédéric Gros (Michel Foucault, París, 1996) a propósito del sentido que Foucault daba a la noción de disciplina.

42 Sobre el tema de las dicotomías existentes en las zonas fronterizas (indios pedestres y ecuestres) véase Vitar, Beatriz: Guerra y misiones en la frontera chaqueña del Tucumán (1700-1767), Madrid, 1997, págs. 225-278. Para un excelente análisis del proceso de gestación del Estado moderno y de "estatalización" de los mecanismos de poder en Europa véase Christin, Olivier: La paix de religion. L'autonomisation de la raison politique, París, 1997. 